\title{
Method of Restoring Parameters of Information Objects in a Unified Information Space Based on Computer Networks
}

\author{
Vadym Mukhin \\ National Technical University of Ukraine "Igor Sikorsky Kiev Polytechnic Institute”, Kiev, Ukraine \\ E-mail:v.mukhin@kpi.ua \\ Valerii Zavgorodnii \\ State University of Infrastructure and Technologies, Kiev, Ukraine \\ E-mail: zavgorodniivalerii@gmail.com \\ Oleg Barabash \\ State University of Telecommunications, Kiev, Ukraine \\ E-mail: bar64@ukr.net \\ Roman Mykolaichuk \\ Taras Shevchenko National University, Kiev, Ukraine \\ E-mail: mykroman@ukr.net \\ Yaroslav Kornaga \\ National Technical University of Ukraine "Igor Sikorsky Kiev Polytechnic Institute”, Kiev, Ukraine \\ E-mail: y.kornaga@kpi.ua
}

Anna Zavgorodnya

State University of Infrastructure and Technologies, Kiev, Ukraine

E-mail: annzavgorodnya@gmail.com

Vitalii Statkevych

National Technical University of Ukraine "Igor Sikorsky Kiev Polytechnic Institute", Kiev, Ukraine

E-mail: mstatkevich@yahoo.com

Received: 04 February 2019; Accepted: 06 March 2020; Published: 08 April 2020

\begin{abstract}
The paper describes the organization of the unified information space which is based on the uniform principles and the general rules that ensure the informational interaction of objects.

In practice, in case when the communication with an information object of the unified information space is lost, the necessary information about this object should be collected by the analysis of previous interactions of the information object with the other information objects. The goal of this paper article is to develop a mechanism that will allow restore the missing parameters of information objects in case of communication loss with this object.

There was performed the experimental researches with the proposed mechanisms. The experiments have shown that there is an unequivocal relationship between the quality of restoration of an information object and the topology of links within an unified information space.
\end{abstract}

Index Terms-Unified information space, Information object, Parameters, Communication, Links topology.

\section{INTRODUCTION}

The unified information space (UIS) is an information model of a complex domain. It includes information objects, relations between them, environment of the space and processes accompanying the creation and operation of the UIS. The UIS implies a unified data entry, its storage in uniform formats and unified exchange of information between all information objects [1 - 3].

An unified information space should support the reliably store of the large volume of data of various types, update them quickly, and perform an effective search for the necessary data. Moreover, UIS should provide an unambiguous idea about the content of information and 
its structure. Information in any part of the UIS should be accessible from any other point without additional conversion.

Nowadays, a number of organizations are involved in the development of the UIS, in particular: IEEE (Institute of Electrical and Electronic Engineers), NIST (National Institute of Standards and Technology), ANSI (American National Standard Institute), (all from USA) UKCEB (UK Council for Electronic Business) (UK); Tekes (Finland), etc.

\section{LITERATURE REVIEW}

The study of the problem of formation of the unified information space is actual now. It made by several researcher such as: Abdurakhmanov, Barishpolets, Veprintsev, Grachev, Zuev, Kopylov, Krys'ko, Manilow, Modesto and others [4 - 9].

In [5] was shown that actual is the concept of UIS as a communicative information environment at a certain organization with special feature based on the information flow. Also, there is identified the "nonelectronic" information environment of organization institutions, and "electronic" one as well $[4,6]$.

Unified Information Space is presented in some papers as a set of data, technologies for their support, and the information and telecommunication systems and networks, which are operating on the common principles and general rules that provide information interaction between the organizations and users in order to meet their information needs $[4,5,7]$.

An important component of the UIS design is an unification of information resources of unified information space, which should satisfy certain principles $[4,5,8]$.

The design of UIS should be based on a holistic conception and is based on the specialized information project presented at the level of individual organizations $[6,9]$.

For the formation of the UIS the basic element is information objects (IO). Practically, the UIS includes a set of data, databases and data banks, technologies for their management and use, information and telecommunication systems and networks functioning on the basis of uniform principles and according to general rules providing the information interaction between objects [10 - 16].

In practice, it very often turns out that in the case of loss of communication with an information object, the information about this IO must be collected on the basis of the history of its interaction with other information objects within the framework of the UIS [17 - 22].

Unfortunately, the modern scientific publications on UIS issues are general in nature or are specified in special subject areas. Actual issues relating to the technology for restoring the UIS based on the analysis of the behavior of the IOs and the prehistory of their interaction are almost not considered.

The goal of this article is to develop the method of restoring parameters of information objects in a Unified
Information Space based on computer networks. This method will allow restore the missing parameters of information objects in the case of loss of communication with this object and thereby restore the unity and integrity of the interaction of IO in the UIS.

\section{THE MAIN ELEMENTS OF THE UIS. INTERACTION OF INFORMATION OBJECTS IN THE UIS}

The creation of the UIS is intended to provide access to general information without limiting the space and time. The basis of the UIS is a set of computer systems, local networks, open networks (Internet), software (operating system, application programs, databases, postal services). Also during creation, the means of interfacing various computer systems with each other are formed [3, 17].

Identification of the object in the UIS allows uniquely identify an information object (IO) by its features. To define an IO, identification method can be used based on step-by-step analysis of an object's features using requests to an object in order to provide an opportunity to analyze intermediate results for making decisions on the IO identification [23-25].

The IO identification is performed according to certain external or internal features of the IO, taking into account IO interaction in the UIS. For this each IO is supplied with an IO image - a set of parameters that characterize the object to a certain extent. Similarly, in the form of a brief description - the image of the IO request (IR) - an information request is made to the IO. Due to this, the procedure of identification of the IO comes down to a simple comparison of the IO with the specified image of the request. If the parameters of the IO are necessary and sufficiently coincide with the IR, it is considered that IO is identified [10-13].

The process of placing information objects in the UIS occurs as follows: the initiating subject, as operations are completed, transmits the primary information about the information object to the UIS integrator subject through the communication network [26, 27].

Information objects of a unified information space of an enterprise are processed by integrator subjects to perform their functions in their area of responsibility. The integrator subjects, having received primary information from the initiating subjects, generalize and integrate the information objects of the UIS.

Some of the information is entered into a uniform information base for all subjects to use, and the remaining part of the information is used only by certain subjects who have corresponding access to information.

Integrated objects are used by each local subject to obtain information about the subject area in a unified information space.

The interaction of information objects in the UIS will be presented in the form of a network structure. There are several options for such structures:

1. A fully connected topology (Fig. 1) - each information object is connected with each other (IO1 IO6). However, the number of links is redundant. This 
kind of topology is used relatively rare.

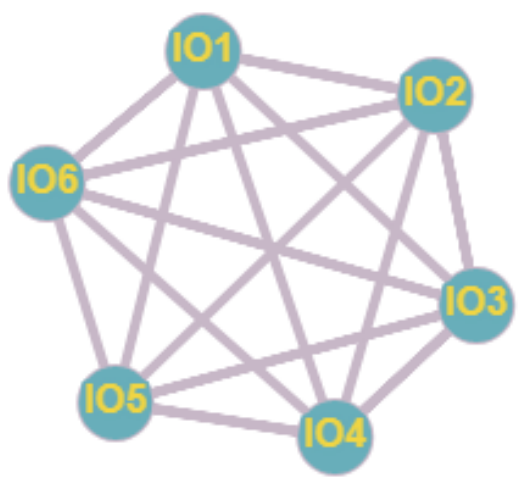

Fig.1. A fully connected topology.

2. Tree topology (Fig. 2) - there is a main information object $\mathrm{IO} 1$ an $\mathrm{d}$ there are objects that are subordinate to it (IO2 - IO6).

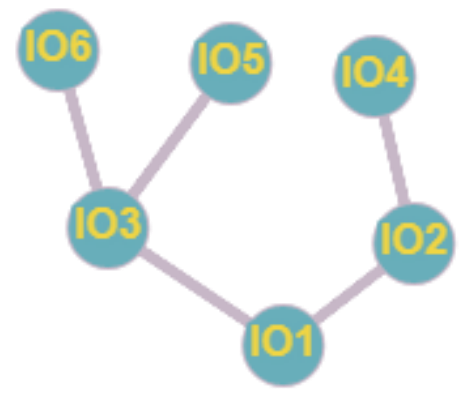

Fig.2. Tree topology.

3. Multi-tiered graph (Fig. 3) - there are only vertical links between information objects (IO1 - IO13).

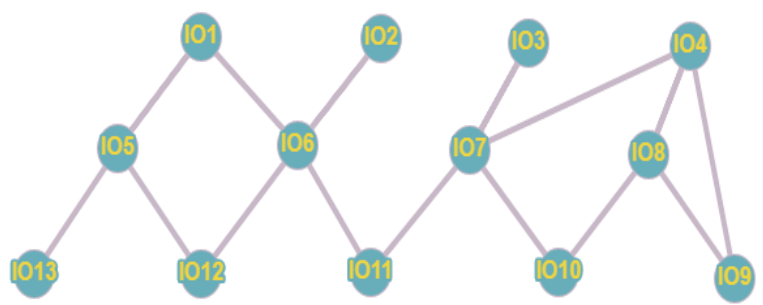

Fig.3. Multi-tiered graph.

\section{METHOD FOR RESTORING THE PARAMETERS OF INFORMATION OBJECTS IN A UNIFIED INFORMATION SPACE}

Consider ten information objects IO1 - IO10 that interact with each other (Fig. 4).

For each information objects the matrix of parameters is constructed. Let each information objects IO1 - IO10 are characterized by five parameters:

Parameter P1 - has a range of values of 0.6 .. 0.9

Parameter P2 - range of values 0.02 .. 0.05

Parameter P3 - range of values 70 .. 90

Parameter P4 - range of values 0.75 .. 0.95
Parameter $\mathrm{P}_{5}$ - range of values 60 .. 80

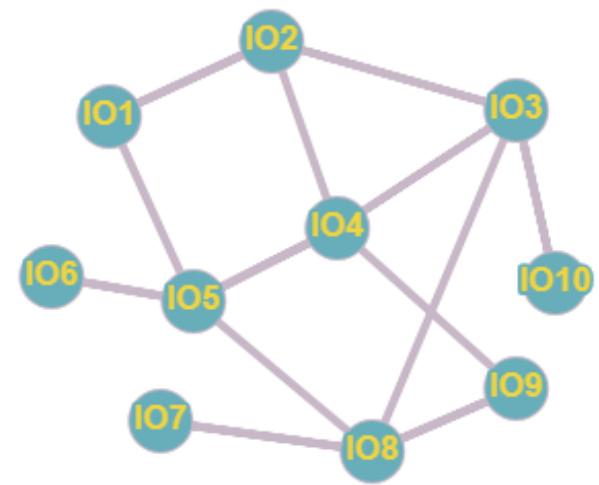

Fig.4. Information objects and links between them.

For each information object, parameter matrices are formed (Table 1):

Table 1. Parameters matrix for each information object

\begin{tabular}{|c|c|c|c|c|c|}
\hline \multirow{2}{*}{} & \multicolumn{5}{|c|}{ Information object $\mathrm{IO}_{1}$} \\
\cline { 2 - 6 } & $\mathrm{P}_{1}$ & $\mathrm{P}_{2}$ & $\mathrm{P}_{3}$ & $\mathrm{P}_{4}$ & $\mathrm{P}_{5}$ \\
\hline $\mathrm{IO}_{1}$ & 0,6 & 0,04 & 71 & 0,75 & 70 \\
\hline $\mathrm{IO}_{2}$ & 0,9 & 0,025 & 89 & 0,78 & 68 \\
\hline $\mathrm{IO}_{3}$ & 0,62 & 0,03 & 72 & 0,8 & 62 \\
\hline $\mathrm{IO}_{4}$ & 0,78 & 0,045 & 78 & 0,92 & 68 \\
\hline $\mathrm{IO}_{5}$ & 0,6 & 0,048 & 83 & 0,9 & 88 \\
\hline $\mathrm{IO}_{6}$ & 0,65 & 0,021 & 82 & 0,87 & 72 \\
\hline $\mathrm{IO}_{7}$ & 0,6 & 0,028 & 81 & 0,91 & 74 \\
\hline $\mathrm{IO}_{8}$ & 0,68 & 0,029 & 77 & 0,93 & 79 \\
\hline $\mathrm{IO}_{9}$ & 0,89 & 0,034 & 74 & 0,83 & 73 \\
\hline $\mathrm{IO}_{10}$ & 0,74 & 0,033 & 86 & 0,89 & 71 \\
\hline
\end{tabular}

\begin{tabular}{|c|c|c|c|c|c|}
\hline \multirow{2}{*}{} & \multicolumn{5}{|c|}{ Information object $\mathrm{IO}_{2}$} \\
\cline { 2 - 6 } & $\mathrm{P}_{1}$ & $\mathrm{P}_{2}$ & $\mathrm{P}_{3}$ & $\mathrm{P}_{4}$ & $\mathrm{P}_{5}$ \\
\hline $\mathrm{IO}_{2}$ & 0,62 & 0,043 & 74 & 0,77 & 60 \\
\hline $\mathrm{IO}_{1}$ & 0,79 & 0,02 & 86 & 0,79 & 69 \\
\hline $\mathrm{IO}_{3}$ & 0,6 & 0,04 & 72 & 0,83 & 68 \\
\hline $\mathrm{IO}_{4}$ & 0,8 & 0,04 & 85 & 0,89 & 79 \\
\hline $\mathrm{IO}_{5}$ & 0,67 & 0,037 & 78 & 0,75 & 74 \\
\hline $\mathrm{IO}_{6}$ & 0,6 & 0,028 & 81 & 0,8 & 66 \\
\hline $\mathrm{IO}_{7}$ & 0,69 & 0,029 & 85 & 0,9 & 78 \\
\hline $\mathrm{IO}_{8}$ & 0,8 & 0,039 & 79 & 0,83 & 74 \\
\hline $\mathrm{IO}_{9}$ & 0,87 & 0,04 & 84 & 0,89 & 78 \\
\hline $\mathrm{IO}_{10}$ & 0,78 & 0,043 & 79 & 0,79 & 66 \\
\hline
\end{tabular}

\begin{tabular}{|c|c|c|c|c|c|}
\hline \multirow{2}{*}{} & \multicolumn{5}{|c|}{ Information object $\mathrm{IO}_{3}$} \\
\cline { 2 - 6 } & $\mathrm{P}_{1}$ & $\mathrm{P}_{2}$ & $\mathrm{P}_{3}$ & $\mathrm{P}_{4}$ & $\mathrm{P}_{5}$ \\
\hline $\mathrm{IO}_{3}$ & 0,68 & 0,035 & 89 & 0,78 & 68 \\
\hline $\mathrm{IO}_{1}$ & 0,78 & 0,045 & 72 & 0,8 & 62 \\
\hline $\mathrm{IO}_{2}$ & 0,61 & 0,033 & 78 & 0,92 & 68 \\
\hline $\mathrm{IO}_{4}$ & 0,87 & 0,05 & 74 & 0,83 & 73 \\
\hline $\mathrm{IO}_{5}$ & 0,65 & 0,047 & 86 & 0,89 & 71 \\
\hline $\mathrm{IO}_{6}$ & 0,85 & 0,024 & 86 & 0,79 & 69 \\
\hline $\mathrm{IO}_{7}$ & 0,68 & 0,02 & 79 & 0,79 & 66 \\
\hline $\mathrm{IO}_{8}$ & 0,84 & 0,02 & 78 & 0,75 & 74 \\
\hline $\mathrm{IO}_{9}$ & 0,87 & 0,04 & 78 & 0,92 & 68 \\
\hline $\mathrm{IO}_{10}$ & 0,72 & 0,03 & 83 & 0,9 & 88 \\
\hline
\end{tabular}




\begin{tabular}{|c|c|c|c|c|c|}
\hline & \multicolumn{5}{|c|}{ Information object $\mathrm{IO}_{10}$} \\
\cline { 2 - 6 } & $\mathrm{P}_{1}$ & $\mathrm{P}_{2}$ & $\mathrm{P}_{3}$ & $\mathrm{P}_{4}$ & $\mathrm{P}_{5}$ \\
\hline $\mathrm{IO}_{10}$ & 0,7 & 0,045 & 74 & 0,83 & 73 \\
\hline $\mathrm{IO}_{1}$ & 0,8 & 0,033 & 86 & 0,89 & 71 \\
\hline $\mathrm{IO}_{2}$ & 0,6 & 0,027 & 89 & 0,78 & 68 \\
\hline $\mathrm{IO}_{3}$ & 0,8 & 0,045 & 72 & 0,8 & 62 \\
\hline $\mathrm{IO}_{4}$ & 0,62 & 0,027 & 78 & 0,92 & 68 \\
\hline $\mathrm{IO}_{5}$ & 0,5 & 0,043 & 86 & 0,79 & 69 \\
\hline $\mathrm{IO}_{6}$ & 0,64 & 0,046 & 78 & 0,92 & 68 \\
\hline $\mathrm{IO}_{7}$ & 0,6 & 0,046 & 83 & 0,9 & 88 \\
\hline $\mathrm{IO}_{8}$ & 0,87 & 0,045 & 72 & 0,8 & 62 \\
\hline $\mathrm{IO}_{9}$ & 0,7 & 0,02 & 79 & 0,79 & 66 \\
\hline
\end{tabular}

If there is no connection for any information objects, i.e. the table that describes the parameters of this object is not available, it is necessary to consider the tables of other information objects with which it interacted, and integrate this data taking into account the weighting factors.

Weights are factors that reflect the significance or "weight" of a given indicator compared with other indicators that influence the information object under study. Thus, with an increase in the number of intermediaries with the help of which an information object interacted with another information object, the weight coefficient value decreases accordingly. As a result, it is necessary to create a new table of parameters for information objects, and to get the parameters themselves from those tables that remain available.

For example, if there is no connection with the IO3 information object, the values of the parameters IO3 (P1), IO3 (P2), IO3 (P3), IO3 (P4) and IO3 (P5) are not known.

We build a new table (matrix) on the basis of links with the information objects with which it interacted (Table 2).

Table 2. The matrix for an IO3 information object based on links with the information objects with which it interacted

\begin{tabular}{|c|c|c|c|c|c|}
\hline \multirow{2}{*}{} & \multicolumn{5}{|c|}{ Information object $\mathrm{IO}_{3}$} \\
\cline { 2 - 6 } & $\mathrm{P}_{1}$ & $\mathrm{P}_{2}$ & $\mathrm{P}_{3}$ & $\mathrm{P}_{4}$ & $\mathrm{P}_{5}$ \\
\hline $\mathrm{IO}_{3}$ & 0,68 & 0,035 & 89 & 0,78 & 68 \\
\hline $\mathrm{IO}_{1}$ & 0,62 & 0,03 & 72 & 0,8 & 62 \\
\hline $\mathrm{IO}_{2}$ & 0,6 & 0,04 & 72 & 0,83 & 68 \\
\hline $\mathrm{IO}_{4}$ & 0,86 & 0,04 & 78 & 0,92 & 68 \\
\hline $\mathrm{IO}_{5}$ & 0,89 & 0,046 & 89 & 0,78 & 68 \\
\hline $\mathrm{IO}_{6}$ & 0,89 & 0,04 & 81 & 0,8 & 66 \\
\hline $\mathrm{IO}_{7}$ & 0,8 & 0,045 & 72 & 0,8 & 62 \\
\hline $\mathrm{IO}_{8}$ & 0,77 & 0,04 & 74 & 0,83 & 73 \\
\hline $\mathrm{IO}_{9}$ & 0,7 & 0,045 & 83 & 0,9 & 88 \\
\hline $\mathrm{IO}_{10}$ & 0,8 & 0,045 & 72 & 0,8 & 62 \\
\hline
\end{tabular}

Next, we build the recovery vector of the parameters P1, P2, P3, P4 and P5 for the information object IO3, taking into account the weighting factors (1):

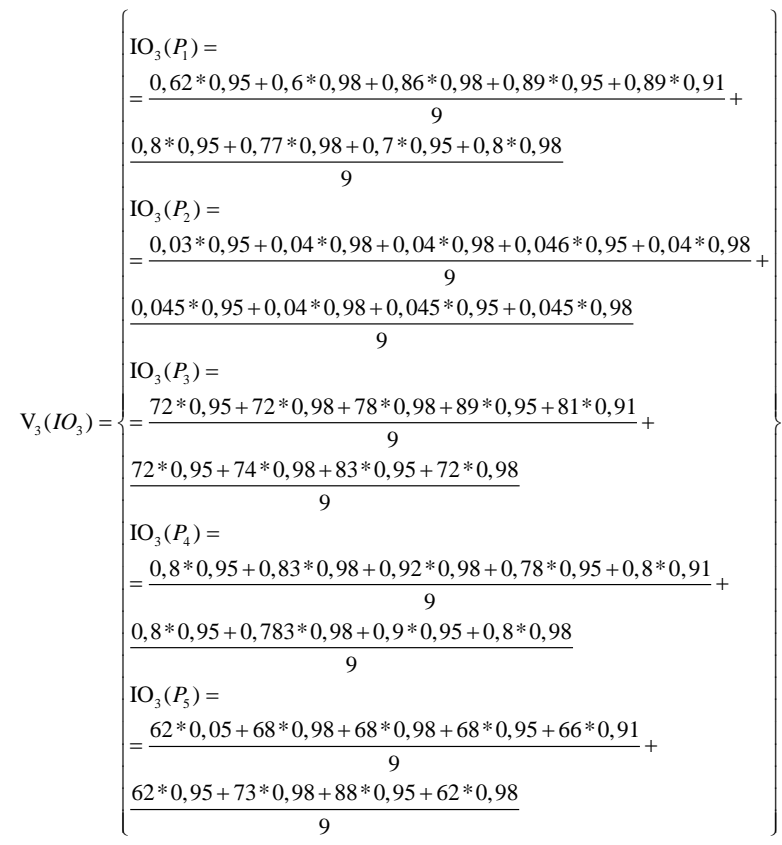

After calculations, we obtain the vector V3 (IO3) and the values of its parameters (2):

$$
\mathrm{V}_{3}\left(\mathrm{IO}_{3}\right)=\left\{\begin{array}{l}
\mathrm{IO}_{3}\left(P_{1}\right)=0,73 \\
\mathrm{IO}_{3}\left(P_{2}\right)=0,039 \\
\mathrm{IO}_{3}\left(P_{3}\right)=73,77 \\
\mathrm{IO}_{3}\left(P_{4}\right)=0,79 \\
\mathrm{IO}_{3}\left(P_{5}\right)=65,73
\end{array}\right\}
$$

The initial vector (with which communication was lost) V3 (IO3) had the following values (3):

$$
\mathrm{V}_{3}\left(\mathrm{IO}_{3}\right)=\left\{\begin{array}{l}
\mathrm{IO}_{3}\left(P_{1}\right)=0,68 \\
\mathrm{IO}_{3}\left(P_{2}\right)=0,035 \\
\mathrm{IO}_{3}\left(P_{3}\right)=89 \\
\mathrm{IO}_{3}\left(P_{4}\right)=0,78 \\
\mathrm{IO}_{3}\left(P_{5}\right)=68
\end{array}\right\}
$$
is (4):

The deviation (the difference of values between vectors)

$$
\operatorname{Vid}_{3}\left(I_{3}\right)=\left\{\begin{array}{l}
\mathrm{IO}_{3}\left(P_{1}\right)=-0,05 \\
\mathrm{IO}_{3}\left(P_{2}\right)=-0,004 \\
\mathrm{IO}_{3}\left(P_{3}\right)=15,23 \\
\mathrm{IO}_{3}\left(P_{4}\right)=-0,01 \\
\mathrm{IO}_{3}\left(P_{5}\right)=2,27
\end{array}\right\}
$$

The deviations obtained for each parameter of the IO3 information object are: 


$$
\begin{gathered}
\text { IO3: } \mathrm{P} 1=7.35 \% ; \mathrm{P} 2=11.43 \% ; \mathrm{P} 3=17.11 \% ; \mathrm{P} 4= \\
1.28 \% ; \mathrm{P} 5=3.34 \%
\end{gathered}
$$

This suggests that it is possible to accurately restore unknown parameters in the absence of communication with an information object.

We considered the case when all the parameters are known in each information object. But in practice this happens quite rarely, therefore, we will further conduct several experiments for the case when unknown information will be present in each information object.

\section{THE EXPERIMENTAL RESEARCH}

Let us perform an analysis of how the topology of IO interaction links affects the restoration of the parameters of information objects.

\section{A. A fully connected topology}

Let us consider a computer network that consists of 10 computers, which will be considered as information objects IO1-IO10 and which interact with each other as shown in Fig. 5.

For each information a matrix of parameters is constructed. Let each information object IO1 - IO10 be characterized by five parameters:

Parameter P1 - random access memory (range of values 1.024GB, 2.048GB, step 0.512GB);

Parameter P2 - memory on the hard drive (range of values $0.24 \mathrm{~Tb}$. $0.360 \mathrm{~Tb}$, step $0.06 \mathrm{~Tb}$ );

Parameter P3 - performance (range of values $2.2 \mathrm{MHz}$.. 2.6 MHz, step 0.2 MHz);

Parameter P4 - bandwidth (range of values 2.048 Mbit / s. 4.096 Mbit / s, step 1.024 Mbit / s);

Parameter P5 - information transfer rate (range of values 1.024 Mbit / s ... 2.048 Mbit / s, step 1.024 Mbit / s).

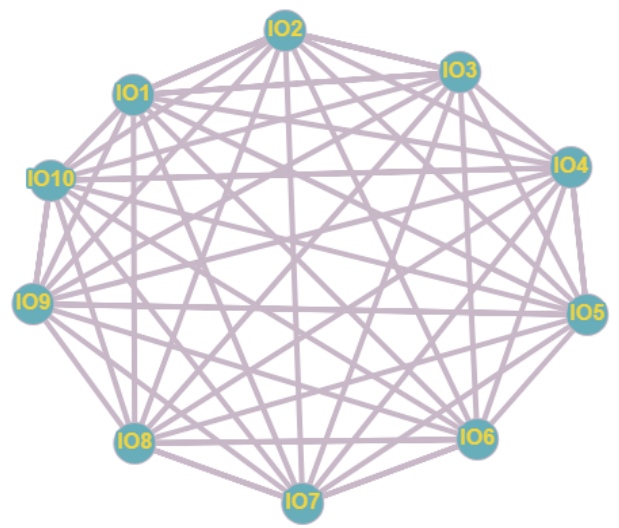

Fig.5. Interaction of information objects with fully connected topology of links

The specified information objects with parameters are presented in table 3 .

\begin{tabular}{|c|c|c|c|c|}
\hline IO1 & $\mathrm{P} 2$ & P3 & P4 & P5 \\
\hline 1.536 & 0.3 & 2.6 & 3.072 & 1.024 \\
\hline 1.536 & 0.24 & 2.4 & 4.096 & 1.024 \\
\hline 1.024 & 0.36 & 2.4 & 4.096 & 1.024 \\
\hline 2.048 & 0.36 & 2.4 & 3.072 & 1.024 \\
\hline 2.048 & 0.24 & 2.4 & 2.048 & 2.048 \\
\hline 2.048 & 0.36 & 2.4 & 3.072 & 1.024 \\
\hline 1.024 & 0.3 & 2.4 & 4.096 & 1.024 \\
\hline 2.048 & 0.3 & 2.4 & 3.072 & 2.048 \\
\hline 1.536 & 0.3 & 2.6 & 2.048 & 2.048 \\
\hline 2.048 & 0.36 & 2.6 & 2.048 & 1.024 \\
\hline IO2 & P2 & P3 & P4 & P5 \\
\hline 1.536 & 0.3 & 2.6 & 2.048 & 2.048 \\
\hline 1.024 & 0.3 & 2.2 & 2.048 & 1.024 \\
\hline 2.048 & 0.24 & 2.4 & 2.048 & 1.024 \\
\hline 2.048 & 0.36 & 2.2 & 2.048 & 1.024 \\
\hline 1.536 & 0.36 & 2.2 & 3.072 & 1.024 \\
\hline 1.536 & 0.36 & 2.4 & 4.096 & 2.048 \\
\hline 2.048 & 0.3 & 2.6 & 3.072 & 2.048 \\
\hline 2.048 & 0.24 & 2.4 & 2.048 & 2.048 \\
\hline 2.048 & 0.36 & 2.2 & 4.096 & 1.024 \\
\hline 2.048 & 0.24 & 2.2 & 3.072 & 1.024 \\
\hline IO3 & $\mathrm{P} 2$ & P3 & P4 & P5 \\
\hline 1.024 & 0.24 & 2.6 & 3.072 & 2.048 \\
\hline 1.536 & 0.36 & 2.6 & 2.048 & 1.024 \\
\hline 2.048 & 0.24 & 2.2 & 4.096 & 1.024 \\
\hline 1.024 & 0.3 & 2.2 & 2.048 & 2.048 \\
\hline 2.048 & 0.3 & 2.4 & 4.096 & 1.024 \\
\hline 2.048 & 0.3 & 2.6 & 3.072 & 1.024 \\
\hline 2.048 & 0.36 & 2.2 & 2.048 & 1.024 \\
\hline 2.048 & 0.24 & 2.4 & 3.072 & 1.024 \\
\hline 1.536 & 0.36 & 2.2 & 3.072 & 1.024 \\
\hline 2.048 & 0.36 & 2.4 & 3.072 & 2.048 \\
\hline
\end{tabular}

Table 3. Information objects IO1-IO10 with parameters

$\begin{array}{cccccc}\text { IO10 } & \text { P1 } & \text { P2 } & \text { P3 } & \text { P4 } & \text { P5 } \\ \text { I1| } & 1.024 & 0.24 & 2.4 & 2.048 & 2.048 \\ \text { I2| } & 2.048 & 0.24 & 2.2 & 3.072 & 1.024 \\ \text { I3| } & 1.536 & 0.3 & 2.2 & 3.072 & 2.048 \\ \text { I4| } & 1.536 & 0.3 & 2.4 & 2.048 & 1.024 \\ \text { I5| } & 1.536 & 0.36 & 2.2 & 4.096 & 2.048 \\ \text { I6| } & 2.048 & 0.3 & 2.4 & 3.072 & 1.024 \\ \text { I7| } & 2.048 & 0.36 & 2.6 & 2.048 & 1.024 \\ \text { I8| } & 2.048 & 0.36 & 2.2 & 2.048 & 2.048 \\ \text { I9| } & 2.048 & 0.24 & 2.6 & 3.072 & 1.024 \\ \text { I10| } & 2.048 & 0.24 & 2.6 & 4.096 & 1.024\end{array}$

Let IO3 be the information object with which communication is lost. The number of intermediaries between IO3 and other information objects is equal to one (since the fully connected network topology is used). Weighting factor for the case of one intermediary equals 0.98 . 
Experiment 1.1. In each information object, all parameters are known. A new table (matrix) is built on the basis of links with those information objects with which IO3 interacted (Table 4).

Table 4. The matrix for an IO3 information object based on links with the information objects with which it interacted

$\begin{array}{cccccc}\mathrm{IO}_{3} \mid & \mathrm{P}_{1} & \mathrm{P}_{2} & \mathrm{P}_{3} & \mathrm{P}_{4} & \mathrm{P}_{5} \\ \mathrm{IO}_{1} \mid & 1.024 & 0.36 & 2.4 & 4.096 & 1.024 \\ \mathrm{IO}_{2} \mid & 2.048 & 0.24 & 2.4 & 2.048 & 1.024 \\ \mathrm{IO}_{3} \mid & 2.048 & 0.24 & 2.2 & 4.096 & 1.024 \\ \mathrm{IO}_{4} \mid & 2.048 & 0.24 & 2.6 & 2.048 & 1.024 \\ \mathrm{IO}_{5} \mid & 1.536 & 0.36 & 2.4 & 2.048 & 1.024 \\ \mathrm{IO}_{6} \mid & 1.536 & 0.3 & 2.2 & 3.072 & 2.048 \\ \mathrm{IO}_{7} \mid & 1.536 & 0.3 & 2.6 & 4.096 & 1.024 \\ \mathrm{IO}_{8} \mid & 1.536 & 0.24 & 2.6 & 3.072 & 1.024 \\ \mathrm{IO}_{9} \mid & 1.536 & 0.24 & 2.2 & 4.096 & 1.024 \\ \mathrm{IO}_{10} \mid & 1.536 & 0.3 & 2.2 & 3.072 & 2.048\end{array}$

Get the result:

Results Vector:

IO3: $\mathrm{P} 1=1.577 ; \mathrm{P} 2=0.2838 ; \mathrm{P} 3=2.376 ; \mathrm{P} 4=3.041$;

$\mathrm{P} 5=1.239$

Initial Vector:

IO3: $\mathrm{P} 1=2.048 ; \mathrm{P} 2=0.24 ; \mathrm{P} 3=2.2 ; \mathrm{P} 4=4.096 ; \mathrm{P} 5=$ 1.024

Deviation:

IO3: P1 $=-0.471(-23 \%) ; \mathrm{P} 2=0.0438(18.25 \%) ; \mathrm{P} 3=$ $0.176(8 \%) ; \mathrm{P} 4=-1.055(-25.75 \%)$;

$\mathrm{P} 5=0.215(21 \%)$

Experiment 1.2. Each information object has up to 10 unknown parameters (how many and which are randomly generated).

Deviation:

IO3: $\mathrm{P} 1=-0.5274(-25.75 \%) ; \mathrm{P} 2=0.03154(13.14 \%)$; $\mathrm{P} 3=0.176(8 \%) ; \mathrm{P} 4=-1.055(-25.75 \%) ; \mathrm{P} 5=0.1165$ (11.37\%)

Experiment 1.3. Each information object has up to 20 unknown parameters (how many and which are randomly generated).

Deviation:

IO3: $\mathrm{P} 1=-0.4429(-21.62 \%) ; \mathrm{P} 2=0.04003(16.68 \%)$; $\mathrm{P} 3=0.0572(2.6 \%) ; \mathrm{P} 4=-1.181(-28.84 \%) ; \mathrm{P} 5=1.521$

Experiment 1.4. Each information object has up to 30 unknown parameters (how many and which are randomly generated).

Deviation:

IO3: $\mathrm{P} 1=-0.5274(-25.75 \%) ; \mathrm{P} 2=0.3564 ; \mathrm{P} 3=0.143$ $(6.5 \%) ; \mathrm{P} 4=-0.7651(-18.68 \%)$;

$\mathrm{P} 5=1.521$

Experiment 1.5. Each information object has up to 40 unknown parameters (how many and which are randomly generated)

Deviation: IO3: $\mathrm{P} 1=-0.426(-20.8 \%) ; \mathrm{P} 2=0.0471$

$(19.63 \%) ; \mathrm{P} 3=2.92 ; \mathrm{P} 4=-1.055(-25.75 \%) ; \mathrm{P} 5=2.028$

Experiment 1.5. Each information object has up to 40 unknown parameters (how many and which are randomly generated).

Deviation: IO3: $\mathrm{P} 1=-0.426(-20.8 \%) ; \mathrm{P} 2=0.0471$ $(19.63 \%) ; \mathrm{P} 3=2.92 ; \mathrm{P} 4=-1.055(-25.75 \%) ; \mathrm{P} 5=2.028$
The graphs are buit of functions of dependences of the absolute values of deviations (in\%) of parameters on the number of unknown parameters in information objects (Table 5, Fig. 6).

Table 5. Value of parameters deviations (in \%) from the number of unknown parameters in information objects

\begin{tabular}{|c|c|c|c|c|c|}
\hline \multirow{2}{*}{$\begin{array}{c}\text { Number of } \\
\text { unknown } \\
\text { parameters }\end{array}$} & \multicolumn{5}{|c|}{ Parameter deviation (\%) } \\
\cline { 2 - 6 } & $\mathbf{P}_{\mathbf{1}}$ & $\mathbf{P}_{\mathbf{2}}$ & $\mathbf{P}_{\mathbf{3}}$ & $\mathbf{P}_{\mathbf{4}}$ & $\mathbf{P}_{\mathbf{5}}$ \\
\hline $\mathbf{0}$ & 23 & 18,25 & 8 & 25,75 & 21 \\
\hline $\mathbf{1 0}$ & 25,75 & 13,14 & 8 & 25,75 & 11,37 \\
\hline $\mathbf{2 0}$ & 21,62 & 16,68 & 2,6 & 28,84 & \\
\hline $\mathbf{3 0}$ & 25,75 & & 6,5 & 18,68 & \\
\hline $\mathbf{4 0}$ & 20,8 & 19,63 & & 25,75 & \\
\hline $\mathbf{5 0}$ & & 23,75 & 13,4 & & 23,75 \\
\hline
\end{tabular}

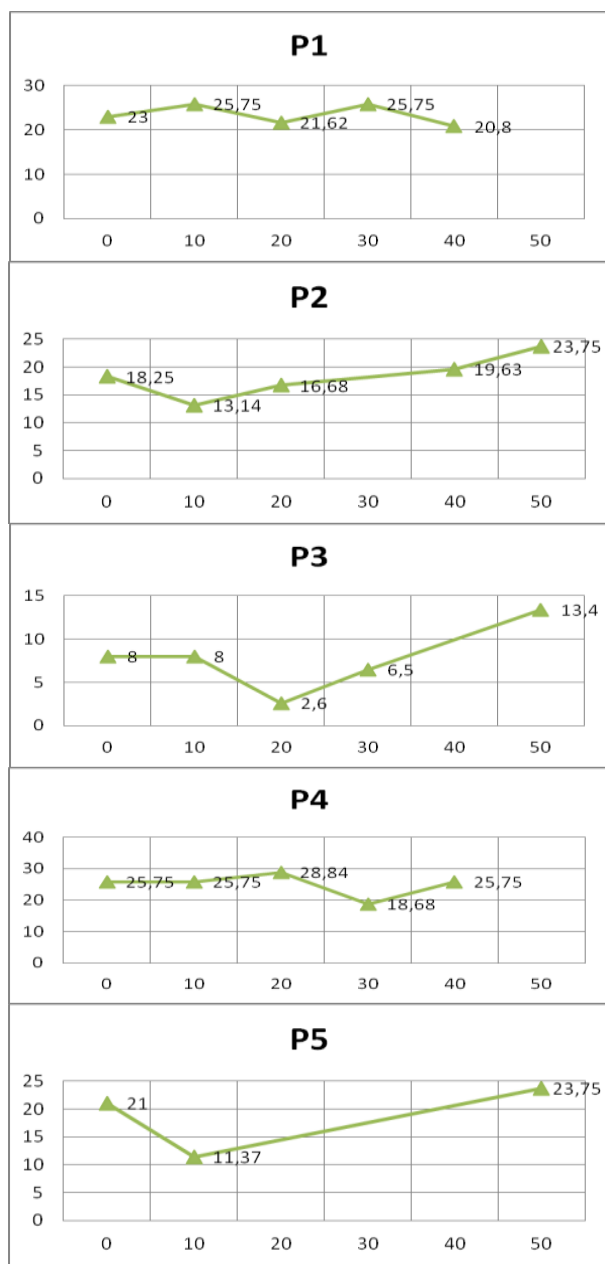

Fig.6. Dependencies of absolute values of parameter deviations on the number of unknown parameters in information objects

In the same way, we conducted 9 more experiments and, using the results obtained, construct graphs of the dependence functions for the absolute values of deviations (in\%) of parameters in each experiment. We calculated the dependencies of absolute values of parameter deviations (in\%) in each experiment for parameters P2, P3, P4 and P5 of the information object IO3. 


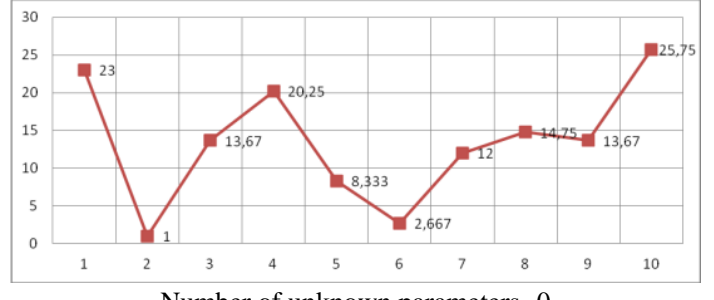

Number of unknown parameters- 0

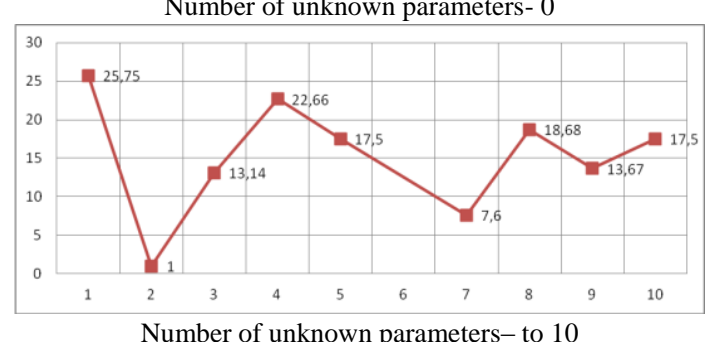

Number of unknown parameters- to 10

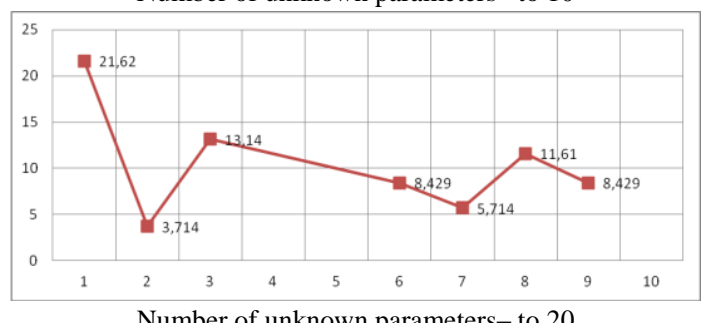

Number of unknown parameters- to 20

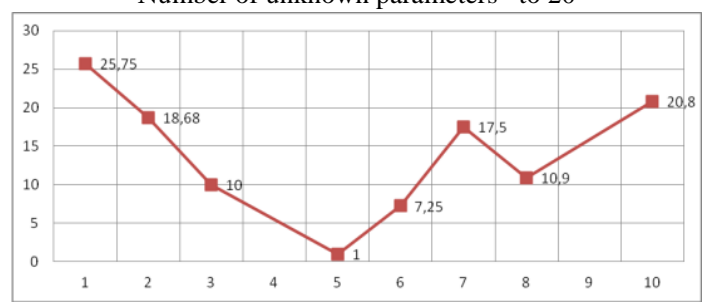

Number of unknown parameters- to 30

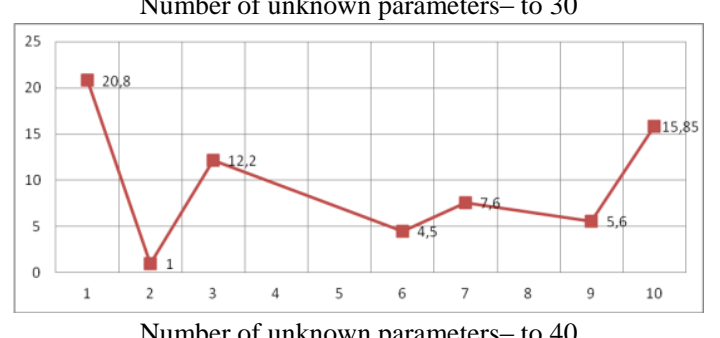

Number of unknown parameters- to 40

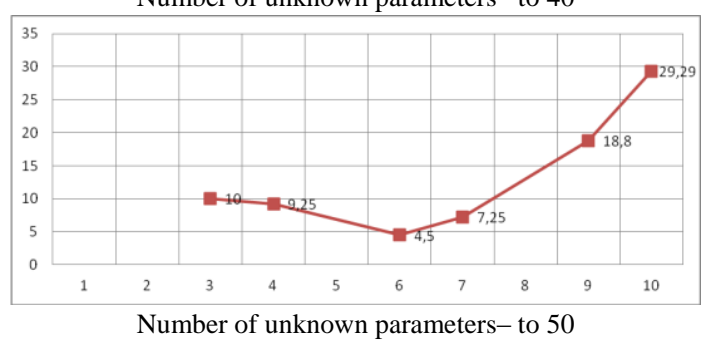

Fig.7. Dependencies of the absolute values of the parameter deviations in each experiment for the parameter P1 of the information object IO3

Next, we averaged the obtained experimental values, and we construct graphs of the dependence functions of the averaged values (in \%) of parameters in 6 experiments. Also, set deviation level to $15 \%$ and deter-mine how many parameters fall into this area (Fig. 8). The value of the deviation level was taken after a detailed analysis of the data obtained, and it corresponds to the level of the data cut-off from the point of view of their reliability.
If the data obtained is below a given level of deviation, then it is considered reliable, i.e. it can be trusted; if above, the data obtained is not reliable, and it cannot be trusted.
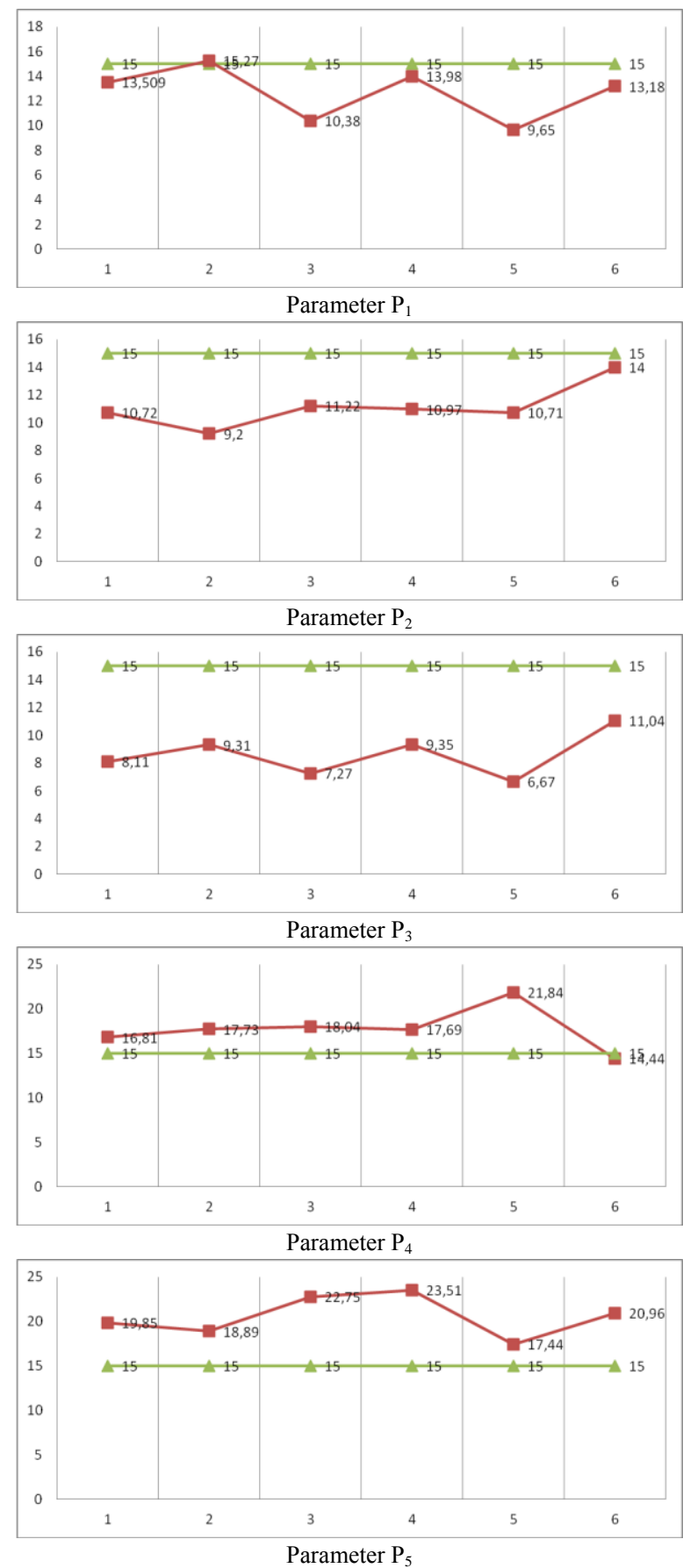

Fig.8. Graphs of the dependence functions of the averaged values of the parameters in six experiments and the deviation level of $15 \%$

Next, let us plot a histogram of the dependence of the parameter values up to the level of $20 \%$ - the critical number (reliability) of the parameters recovery in information objects (Fig. 9). 


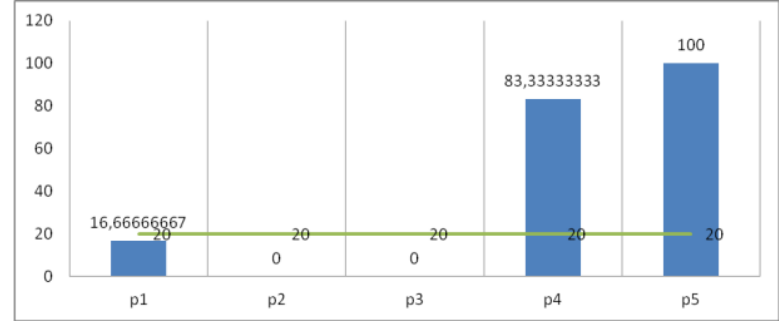

Fig.9. Dependence of parameter values up to the level of $20 \%$

Fig. 9 shows that for a fully connected topology, three parameters (P1, P2 and P3) can be reconstructed with a quite high accuracy, in this case $60 \%$ parameters can be restored.

\section{B. Tree topology}

Consider a computer network, which consists of 10 information objects (computers) IO1-IO10, which interact with each other (Fig. 10).

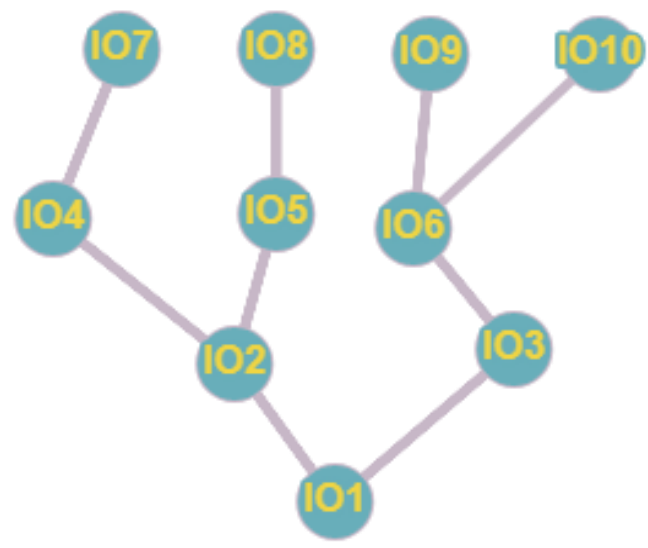

Fig.10. Computer network consisting of 10 information objects (IO1-IO10)

The parameters of information objects (IO1 - IO10) are set in the same way as in the fully connected topology. Information object with which communication is lost IO3. The number of intermediaries between IO3 and others - IO (the count starts from 1):

$\mathrm{IO} 3$ and $\mathrm{IO} 1=1 ; \mathrm{IO} 3$ and $\mathrm{IO} 2=2 ; \mathrm{IO} 3$ and $\mathrm{IO} 4=3$; $\mathrm{IO} 3$ and $\mathrm{IO} 5=3$; IO3 and $\mathrm{IO} 6=1$;

$\mathrm{IO} 3$ and $\mathrm{IO} 7=4 ; \mathrm{IO} 3$ and $\mathrm{IO} 8=4 ; \mathrm{IO} 3$ and $\mathrm{IO} 9=2$; $\mathrm{IO} 3$ and $\mathrm{IO} 10=2$

Weights:

If there is 1 intermediary $=0.98$;

In the case of 2 intermediaries $=0.96$;

In case of presence of 3 intermediaries $=0.94$;

In case of 4 intermediaries $=0.92$.

Similarly, experiments were conducted for tree topology and the following results were obtained:

The graphs of the dependence functions of the averaged values (in \%) of the parameters in six experiments are presented in Fig. 11. Also, set the deviation level to $15 \%$ and determine how many parameters fall in this area.
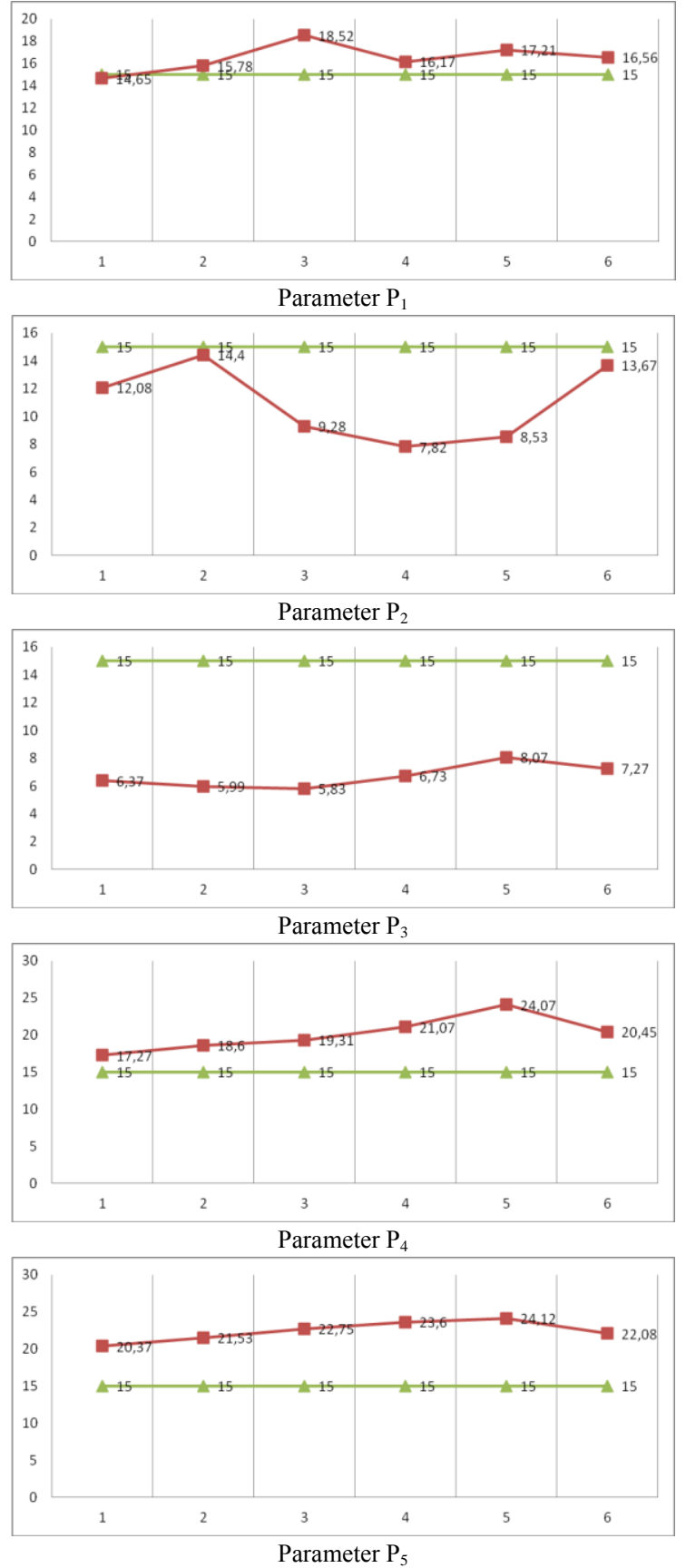

Fig.11. Graphs of the dependence functions of the averaged values of the parameters in six experiments and the level of deviation of $15 \%$

The histogram of the dependence of the values of parameters up to the level of $20 \%$ is shown in Fig. 12.

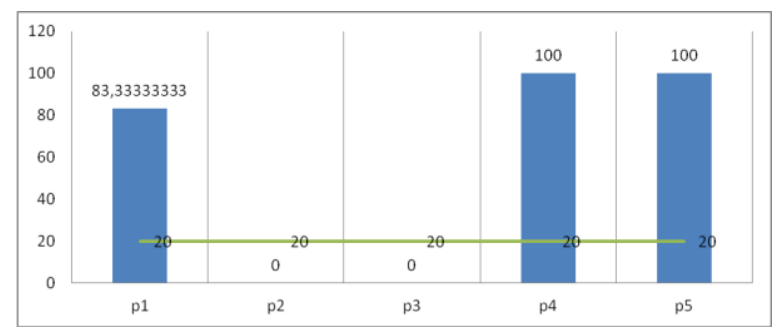

Fig.12. Dependence of parameter values up to the level of $20 \%$ 
From the histogram, it can be seen that with tree topology, two parameters (P2 and P3) can be reconstructed in this case with accuracy of $40 \%$ parameters can be restored.

\section{Multi-tiered graph}

Consider a computer network, which consists of 10 information objects (computers) IO1-IO10, which interact with each other (Fig. 13).

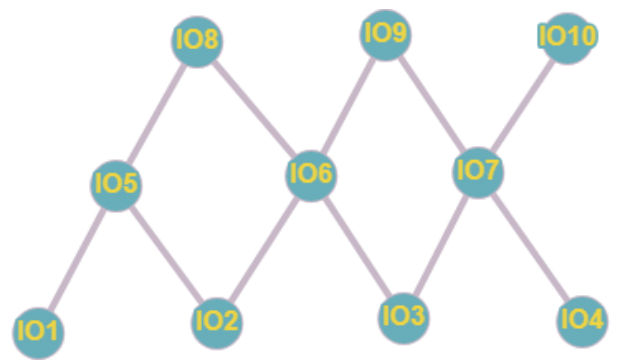

Fig.13. A computer network consisting of 10 information objects (IO1-IO10)

The parameters of information objects (IO1 I10) are set in the same way as in the fully connected topology. Information object with which communication is lost - is IO3. The number of intermediaries between IO3 and others - IO (the count starts from 1):

$\mathrm{IO} 3$ and $\mathrm{IO} 1=4 ; \mathrm{IO} 3$ and $\mathrm{IO} 2=2 ; \mathrm{IO} 3$ and $\mathrm{IO} 4=2$; $\mathrm{IO} 3$ and $\mathrm{IO} 5=3 ; \mathrm{IO} 3$ and $\mathrm{IO} 6=1$;

$\mathrm{IO} 3$ and $\mathrm{IO} 7=1 ; \mathrm{IO} 3$ and $\mathrm{IO} 8=2 ; \mathrm{IO} 3$ and $\mathrm{IO} 9=2$; $\mathrm{IO} 3$ and $\mathrm{IO} 10=2$

Weights:

If there is 1 intermediary $=0.98$;

In the case of 2 intermediaries $=0.96$;

In case of presence of 3 intermediaries $=0.94$;

In case of 4 intermediaries $=0.92$.

Similarly, experiments were conducted for multi-tiered graph and the following results were obtained:

The graphs of the functions of the dependences of the averaged values (in\%) of the parameters in six experiments are presented in Fig. 14. Also, set the deviation level to $15 \%$ and determine how many parameters fall in this area.

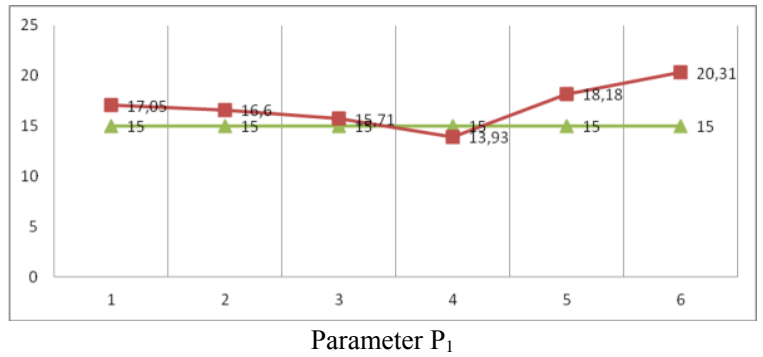

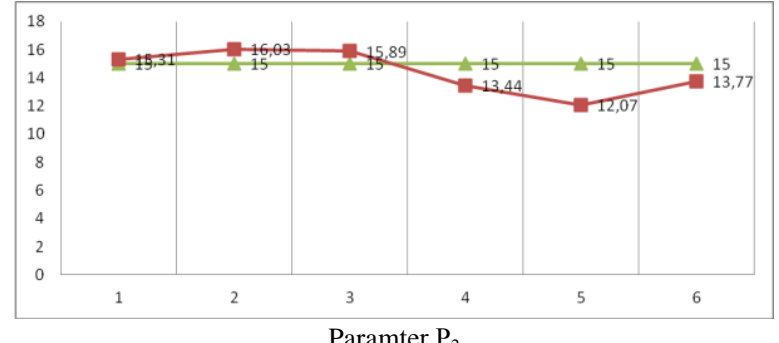
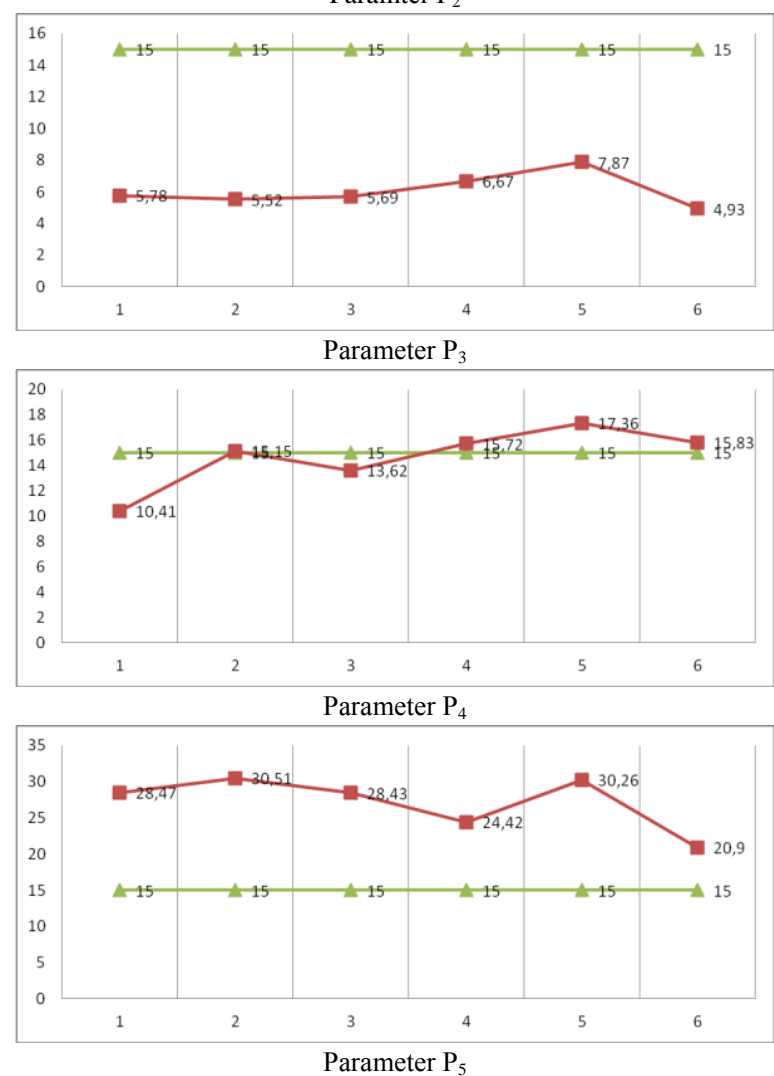

Fig.14. Graphs of the dependence functions of the averaged values of the parameters in six experiments and the deviation level of $15 \%$

The histogram of the dependence of the values of the parameters up to the level of $20 \%$ is shown in Fig. 15.

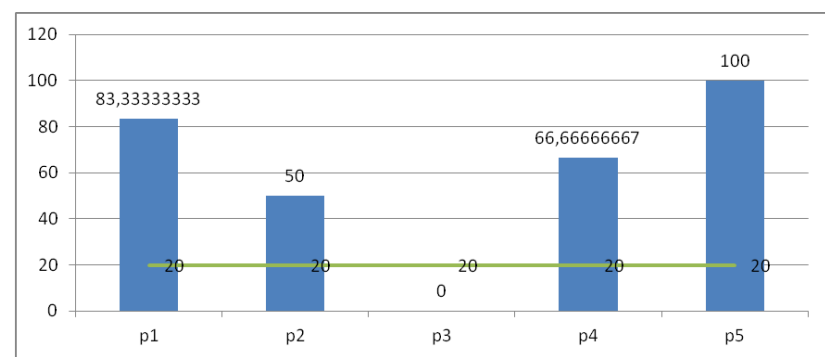

Fig.15. Dependence of parameter values up to the level of $20 \%$ 
From the histogram (Fig. 15) it can be seen that in the multi-tiered graph one parameter (P3) can be reconstructed in this case with accuracy of $20 \%$ parameters can be restored.

\section{CONCLUSIONS}

The article describes a method for calculating averaged values taking into account weights for restoring lost parameters of information objects, which was applied in turn to three network topologies: fully connected topology, tree topology and a multi-tiered graph. Using this technology, we experimentally found that when using it for a fully connected topology, we can recover (get reliable data) three parameters out of five, in tree topology two parameters out of five, and in a multilevel graph one parameter out of five. That is, we prove that here is a clear dependence of the obtained results about the parameters restoration from the selected topologies.

Thus, for the formation of the structure of relations between the information objects in a single information space, the most optimal is the topology with a fully connected links between the information objects. In the case if there is possible to form this topology, then it is most preferable. As an alternative, we may use a tree topology, but it provides the lower accuracy of parameter recovery compared to a fully connected one and can be effective, specially in the case when there are exist the formal hierarchical relationships and links between information objects in the single information space.

In order to form efficiently an unified information space and to achieve high-quality results, it is necessary to develop: algorithms and software tools to support the technology of recovery of information objects based on the results of their interaction in the unified information space; create a set of tools for the formation of the UIS on the basis of existing individual mechanisms for IO supporting; create the testing tools for the mechanisms for UIS forming.

\section{REFERENCES}

[1] M. Gershkovich, and K. Birukova, "The tasks of identification of information objects in area-spread data arrays," Systems and means of information, Vol. 24, issue 1, 2014. - pp. 224-243.

[2] M. Arenas, B. Cuenca Grau, E. Kharlamov, S. Marciuska, and D. Zheleznyakov, "Faceted search over RDF-based knowledge graphs," J. Web Semantics, 37, 2016, pp. 5574.

[3] M. Arenas, B. Cuenca Grau, E. Kharlamov, S. Marciuska, and D. Zheleznyakov, "Enabling Faceted Search over OWL 2 with SemFacet," In Proc. of OWLED, 2014, pp. 121-132.

[4] E. Eliseeva, I. Shcherba, S. Morozova, E. Shadoba, L. Petukhova, N. Seregina. Technological and Methodological Approaches to the Design of Information and Educational Space of Modern High School. International Review of Management and Marketing, Vol. 6, Special Issue (S1), 2016. - pp.135 -141.

[5] E.Yastrebtseva, My province - The center of the universe. The development of telecommunications activities in the regions. Moscow: YUNPRESS. 1999. - p225

[6] V.B. Moiseev. Information Technology in Higher Education. Penza: Publisher of Penza Institute of Technology, 2002.

[7] B.S. Akhmetov. Features of the construction of information educational environment of in high school. Proc. of VIII International Conference "The use of new technologies in education". Troitsk: FNTO "Baytik", 2002 - p15-16.

[8] I.A. Tagunova. Model of world education in the context of the Internet. Bulletin of Moscow University. Pedagogical Education, N4,2009. -p. 3-16.

[9] L.N. Kechiev, G.P. Putilov, S.R. Tumkovsky, Preparation of teaching materials for inclusion in the educational environment. Moscow: MIEM., 1999. - p34.

[10] E. Sherkhonov, and M. Marx, "Containment of acyclic conjunctive queries with negated atoms or arithmetic comparisons," Information Processing Letters, 120, 2017.

[11] A. Soylu, M. Giese, R. Schlatte, E. Jim’enez-Ruiz, E. Kharlamov, O.L. Ozcep, C. Neuenstadt, and S. Brandt, "Querying industrial stream-temporal data: An ontologybased visual approach," J. AISE, 9(1), 2017.

[12] M. Kaminski, E.V. Kostylev, and B. Cuenca Grau, "Semantics and expressive power of subqueries and aggregates in SPARQL 1.1," In: Proc. of WWW, 2016.

[13] D.F. Huynh, and D.R. Karger, "Parallax and companion: Set-based browsing for the Data Web," http://davidhuynh.net/media/papers/2009/www2009parallax.pdf, 2013.

[14] Y. Tzitzikas, N. Manolis, and P. Papadakos, "Faceted exploration of RDF/S datasets: A survey," J. Intell. Inf. Syst, 2017.

[15] Z.Hu, V. Mukhin, Y.Kornaga, A.Volokyta, O. Herasymenko. "The scheduler for distributed computer systems based on the network centric approach to resources control". Proc. of the 2017 IEEE 9th International Conference on Intelligent Data Acquisition and Advanced Computing Systems: Technology and Applications, "IDAACS 2017”, 21-23 Sept., 2017, Bucharest, Romania. - pp. 518-523.

[16] V.Mukhin, Y. Romanenkov, J. Bilokin, A. Rohovyi, A. Kharazii, V. Kosenko, N. Kosenko, J. Su. "The method of variant synthesis of information and communication network structures on the basis of the graph and settheoretical models". International Journal of Intelligent Systems and Applications (IJISA), 9(11), 42-51, 2017.

[17] M. Arenas, B. Cuenca Grau, E. Kharlamov, S. Marciuska, D. Zheleznyakov, and Yujiao Zhou, "Querying Life Science Ontologies with SemFacet," In Proc. of SWAT4LS, 2014.

[18] G. Aluç, O. Hartig, T. Ozsu, and K. Daudjee, "Diversied stress testing of RDF data management systems," In ISWC, 2014, pp. 197-212.

[19] M. Arenas, B. Cuenca Grau, E. Kharlamov, S. Marciuska, and D. Zheleznyakov, "On Faceted Search over Knowledge Bases," In Proc. of DL, 2014, pp. 153-156.

[20] M. Arenas, B. Cuenca Grau, E. Kharlamov, S. Marciuska, D. Zheleznyakov, and E. Jiménez-Ruiz, "SemFacet: Semantic Faceted Search over Yago," In Proc. of WWW (Companion Volume), 2014, pp. 123-126.

[21] B. Motik, Y. Nenov, R. Piro, I. Horrocks, and D. Olteanu, "Parallel Materialisation of Datalog Programs in Centralised, Main-Memory RDF Systems," In Proc. of AAAI, 2014, pp. 129-137.

[22] P. Fafalios, and Y. Tzitzikas, "X-ENS: Semantic Enrichment of Web Search Results at Real-Time," In Proc. of SIGIR, 2013, pp. 1089-1090. 
[23] R.J. Little, and D.B. Rubin, "Statistical analysis with missing data," Vol. 793, 2019.

[24] K. Smelyakov, I. Ruban, D. Sandrkin, V. Martovytskyi, and Y. Romanenkov, "Search by Image. New Search Engine Service Model" 2018 5th International ScientificPractical Conf. Problems of Infocommunications. Science and Technology (PIC S\&T), 9-12, 2018, pp. 181-186.

[25] S. Bielievtsov, I. Ruban, K. Smelyakov, and D. Sumtsov, "Network technology for transmission of visual information," Selected Papers of the XVIII Intern. Scientific and Practical Conf. on Information Technologies and Security (ITS 17.05.2018). - CEUR Workshop Processing, Kyiv, Ukraine, Nov. 27, 2018, pp. 160-175.

[26] S. Ferr'e, and A. Hermann, "Semantic search: Reconciling expressive querying and exploratory search," In: Proc. of ISWC, 2011.

[27] M. Arenas, B. Cuenca Grau, E. Kharlamov, S. Marciuska, and D. Zheleznyakov, "Semfacet: Faceted search over ontology enhanced knowledge graphs," In ISWC Posters \& Demos, 2016.

\section{Authors' Profiles}

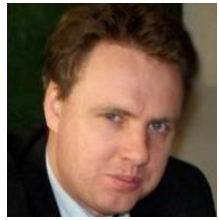

Vadym Mukhin: Professor of department of the mathematical methods of system analysis of National Technical University of Ukraine "Kiev Polytechnic Institute", Doct. of Sc.

Born on November 1, 1971. M. Sc. (1994), PhD (1997), Doct. of Sc. (2015) from the National Technical University of Ukraine "Kiev Polytechnic Institute"; Professor (2015).

Major interest: the security of distributed computer systems and risk analysis; design of the information security systems; mechanisms for the adaptive security control in distributed computing systems; the security policy development for the computer systems and networks.

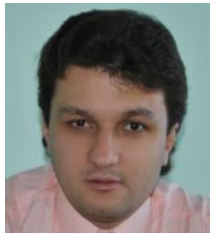

Valerii Zavgorodnii: Assoc. professor of Information Technologies Department of the State University of Infrastructure and Technologies, PhD.

Born on May 25, 1982. PhD (2013) from Kremenchuk Mykhailo Ostrohradskyi National University; Assoc. Prof. (2015) of Department of Systems Software.

Major interest: information technologies, databases, decision support systems, introduction of Information and communication technology in the educational process.

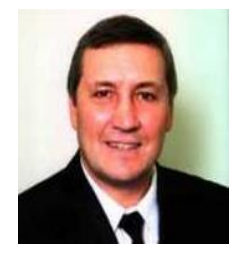

Oleg Barabash: Chair of high mathematics department of State University of Telecommunications, Ukraine, Kiev, Doct. of Sc.

Born on July 28, 1964. M. Sc. (1986), PhD (1992), Doct. of Sc. (2006) from the National Academy of Defence of Ukraine; Assoc. Prof. (1996), Professor (2007) of computer systems department.

Major interest: the functional stability of information systems and diagnostic systems for digital objects; security of distributed computer systems; design of the information security systems computer systems; design of the information security systems.

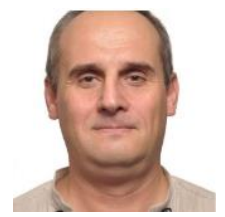

Roman Mykolaichuk: Associate Professor of the Department of Network and Internet Technologies, Doctor of Technical Sciences.

Doctor of Technical Sciences (2014), Associate Professor (2008).

Author of more than 100 scientific papers and patents.

Major interest: the functioning of the robotic and other complex technical systems with complex dynamic structure.

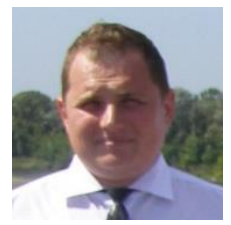

Yaroslav Kornaga: Assoc. professor of computer systems department of National Technical University of Ukraine "Kiev Polytechnic Institute", PhD.

Born on January 1, 1982. M. Sc. (2005), $\mathrm{PhD}$ (2015), from State University of Telecommunications; Assoc. Prof. (2015) of techical cybernetics department.

Major interest: the security of distributed database and risk analysis; design of the distributed database; mechanisms for the adaptive security control in distributed database; the security policy development for distributed database.

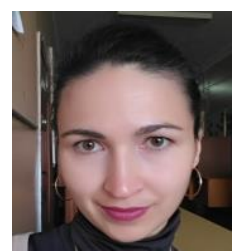

Anna Zavgorodnya: Senior teacher of Information Technologies Department of the State University of Infrastructure and Technologies.

Born on January 12, 1989. M. Sc. (2011)

Major interest: software engineering, databases, information systems, business process management.

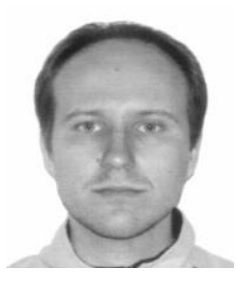

Vitalii Statkevych: Researcher, Department of applied nonlinear analysis in Institute for Applied System Analysis, Igor Sikorsky Kyiv Polytechnic Institute, Ph.D.

Born in 1985, M.Sc. (2008), Ph.D. (2012), researcher of Department of applied nonlinear analysis (2011), assistant professor of Department of the Mathematical Methods of System Analysis (2012).

Major interest: functional analysis, essentially infinitedimensional differential operator of the Laplace-Levy type; Petri nets.

How to cite this paper: Vadym Mukhin, Valerii Zavgorodnii, Oleg Barabash, Roman Mykolaichuk, Yaroslav Kornaga, Anna Zavgorodnya, Vitalii Statkevych, "Method of Restoring Parameters of Information Objects in a Unified Information Space Based on Computer Networks", International Journal of Computer Network and Information Security(IJCNIS), Vol.12, No.2, pp.11-21, 2020. DOI: 10.5815/ijcnis.2020.02.02 